\title{
La función pública de los Secretarios e Interventores de la Administración local
}

\author{
Ángel Sánchez Blanco \\ Catedrático de Derecho Administrativo \\ Universidad de Málaga
}

\begin{abstract}
SUMARIO: I. EL CONTENIDO DE LA ACTIVIDAD FUNCIONARIAL DE SECRETARIOS E INTERVENTORES DE LA ADMINISTRACIÓN LOCAL. II. LA MODULACIÓN DE LOS REQUERIMIENTOS DE MÉRITO Y CAPACIDAD PARA EL ACCESO A LA FUNCIÓN DE SECRETARÍA E INTERVENCIÓN LOCAL, Y LA MODULACIÓN DEL ESQUEMA DE OBJETIVIDAD, IMPARCIALIDAD E INDEPENDENCIA EN EL EJERCICIO DE LA FUNCIÓN DE SECRETARÍA E INTERVENCIÓN LOCAL. III. LA RUPTURA DEL ESQUEMA DE OBJETIVIDAD, IMPARCIALIDAD E INDEPENDENCIA EN EL EJERCICIO DE LA FUNCIÓN DE SECRETARÍA E INTERVENCIÓN LOCAL, POR LA QUIEBRA DE LA GARANTÍA DE MÉRITO Y CAPACIDAD EN EL ACCESO A LOS PUESTOS PÚBLICOS DE SECRETARIO E INTERVENTOR LOCAL. 1. Exposición de la doctrina del Tribunal Constitucional. 2. Valoración de la doctrina del Tribunal Constitucional.
\end{abstract}

\section{EL CONTENIDO DE LA ACTIVIDAD FUNCIONARIAL DE SECRETARIOS E INTERVENTORES DE LA ADMINISTRACIÓN LOCAL}

La figura del secretario municipal y del interventor municipal materializan la respuesta del ordenamiento jurídico a las peculiaridades de la Administración local. Es una equilibrada respuesta técnico jurídica para procedimentalizar las actuaciones de los órganos colegiados municipales, predeterminados por la condición política de sus miembros, electos por los ciudadanos por el sistema de listas cerradas.

El pleno de cada Ayuntamiento o el pleno de cada Diputación Provincial, presidido por el Alcalde o el Presidente de la Diputación, requiere de la activa presencia de cada Secretario para la celebración de cada sesión plenaria y la válida adopción y ejecución de sus acuerdos: el secretario formaliza la citación a los miembros del Pleno, informa en Derecho los asuntos que materializan el orden del día del plenario; elabora el acta de la sesión, dando fe pública de los asistentes, de las deliberaciones, de los acuerdos adoptados y de las votaciones que los avalan, de las que pueden derivarse eventuales responsabilidades, y asume la elaboración de los documentos relativos a cada acuerdo adoptado por el Pleno a efectos de su ejecución. 
La actividad del Ayuntamiento o Diputación requiere de la actividad profesional del Interventor en la tramitación de los procedimientos que tengan contenido económico. La aplicación de cada partida presupuestaria está condicionada a la conformidad del Interventor, en calidad de funcionario responsable de la adecuación de la gestión económica de cada Ayuntamiento o Diputación a los requisitos que establece la legislación de haciendas locales.

Secretario e Interventor tienen atribuida la misión de formalizar en Derecho la actividad de los distintos órganos de los Ayuntamientos y Diputaciones, transformando la iniciativa política de los acuerdos adoptados en los correspondientes plenos por los concejales o diputados provinciales, en normas municipales o provinciales homologadas en Derecho, o en resoluciones administrativas adoptadas conforme a los requerimientos exigidos por el procedimiento común de las Administraciones públicas y con respeto a los derechos ciudadanos reconocidos en las bases del régimen jurídico de las Administraciones Públicas.

La Ley 30/1992-4/1999, de Régimen Jurídico de las Administraciones Públicas y del Procedimiento Administrativo Común, con la supeditación a plazo de las notificaciones de resolución de los procedimientos administrativos, unido a la línea tendencial de reconocimiento de efectos positivos a las pretensiones tramitadas ante las Administraciones públicas en caso de silencio o inactividad administrativa, aportan a Secretarios e Interventores municipales y provinciales un mayor contenido a sus funciones públicas: ser, en su condición de responsables jurídicos y económicos del ente local, la garantía de la adecuación de Ayuntamientos y Diputaciones a los requerimientos procedimentales establecidos por la legislación.

La Ley 7/1985, Básica de Régimen Local, en su artículo 92.3, aporta el marco jurídico a las funciones de Secretarios e Interventores de la Administración Local: califica sus funciones como «necesaria en todas las Corporaciones locales», y define sus contenidos: «la de Secretaría, comprensiva de la fe pública y el asesoramiento legal preceptivo», y la de Intervención, a la que se atribuye «el control y la fiscalización interna de la gestión económicofinanciera y presupuestaria y la contabilidad, tesorería y recaudación».

El régimen jurídico de la prestación de las funciones de Secretaría e Intervención es definido por el mismo artículo 92 de la Ley Básica de Régimen Local, en su punto 2: «personal sujeto al estatuto funcionarial», que, junto a aquellos que «impliquen ejercicio de autoridad», se dispone «se reserven a los funcionarios para la mejor garantía de la objetividad, imparcialidad e independencia en el ejercicio de la función». 
El carácter funcionarial de Secretarios e Interventores agrega una peculiaridad adicional el formar parte de una categoría especial: «Personal habilitado al efecto con carácter nacional» ${ }^{1}$. Este concepto o el de «funcionarios con habilitación de carácter nacional», adecua a la sensibilidad autonómica el anterior concepto de «Cuerpos Nacionales de Administración Local», y crea, en el estatuto jurídico de Secretarios e Interventores de Administración Local, una situación peculiar: son funcionarios públicos con una situación jurídica que se disocia, entre su relación de servicio, con la Administración General del Estado, y su relación orgánica, con el correspondiente Ayuntamiento o Diputación.

La función de Secretarios e Interventores de la Administración local cumple una doble función: prestar el asesoramiento legal y la fiscalización de la gestión económica en cada Ayuntamiento o Diputación y, al tiempo, hacerlo con aplicación de unos parámetros básicos para el conjunto de los Ayuntamientos y Diputaciones del Estado, garantizando el tratamiento común de los ciudadanos en el conjunto plural y diverso de municipios y Diputaciones Provinciales, sin poder olvidar la función de Secretarios e Interventores en Mancomunidades, Consorcios, Comarcas y Áreas Metropolitanas, en calidad de importantes figuras asociativas de nuestras Administraciones locales.

La actividad funcionarial de Secretarios e Interventores es, por lo expuesto, de carácter necesario en todas las Corporaciones locales, y mediante sus servicios, de estricto carácter funcionarial, el Estado descentralizado de las Autonomías, locales y de nacionalidades y de regiones, articula el referente unitivo que hace posible materializar las bases del régimen jurídico de las Administraciones Públicas, el procedimiento administrativo común y la homogeneidad en la materialización de los derechos de los ciudadanos ante las Administraciones locales, con la transcendencia de que la Administración local es la entrada del vecino del correspondiente municipio, a través de su Ayuntamiento, al resto de las Administraciones públicas mediante el sistema intercomunicado de registros que propicia la Ley de Régimen Jurídico de las Administraciones Públicas ${ }^{2}$.

El carácter necesario de las funciones públicas de Secretarios e Interventores de la Administración Local, su contribución pública a la articula-

\footnotetext{
${ }^{1}$ Conforme a las previsiones de los artículos 98 y 99 de la referida Ley 7/1985, Básica de Régimen Local, artículos 158 a 166 del Real Decreto Legislativo 781/1986, de disposiciones legales vigentes de régimen local, y Real Decreto 1174/1987, sobre régimen jurídico de los funcionarios con habilitación de carácter nacional.
}

${ }^{2}$ Artículos 38.4,e); 45, y 70.1,a), de la Ley 30/1992-4/1999. 
ción de la diversidad y pluralidad del Estado descentralizado, justifican el régimen estatutario bifronte: estatal y local.

Las funciones de Secretario e Interventor están condicionadas, por los términos del artículo 103 de la Constitución: los «principios de mérito y capacidad» en el «acceso a la función pública», y «las garantías para la imparcialidad en el ejercicio de sus funciones». El artículo 92.2 de la Ley 7/1985, Básica de Régimen Local, sintetiza, los condicionantes que afectan el estatuto jurídico del Secretario y el Interventor: la vinculación de sus funciones a un régimen estatutario funcionarial, como fórmula «para la mejor garantía de la objetividad, imparcialidad e independencia en el ejercicio de la función».

La legislación de régimen local ha ofrecido pormenorizada respuesta a las situaciones administrativas de los funcionarios de Secretaría e Intervención, en coherente adecuación a las muy diversas situaciones de población y presupuesto de las Corporaciones locales. Configura una escala diferenciada de las de Administración General y Administración Especial, previstas en el artículo 167 del Real Decreto Legislativo 781/1986, integrada por tres subescalas: Secretaría, Intervención-Tesorería y Secretaría-Intervención, dentro de las cuales, y con la excepción de la subescala de Secretaría-Intervención, se distinguen, conforme al artículo 20.1 del Real Decreto 1174/1987, las categorías de entrada y superior.

El tipo de Corporación local o la población con que cuenta es determinante, en aplicación del artículo 2 del Real Decreto 731/1993, de la clasificación de los puestos de trabajo que pueden desempeñar los funcionarios de cada subescala y categoría. En esta línea, se clasifican como Secretarías de primera clase, reservadas a funcionarios de la subescala de Secretaría con categoría superior, conforme al artículo 2.a) del Real Decreto 731/1993, las de las Diputaciones Provinciales, Cabildos y Consejos Insulares; Ayuntamientos que sean capitales de Comunidad Autónoma y de Provincia, y municipios con población superior a 20.000 habitantes y, el artículo 2.d) del mismo Real Decreto, califica como Intervenciones de clase primera los puestos de intervención con Secretarías de clase primera, y que están reservadas a funcionarios pertenecientes a la subescala de Intervención-Tesorería de categoría superior.

El sistema de concurso con valoración de méritos generales y los específicos adecuados a las características del puesto ha sido el procedimiento de selección de los funcionarios de Secretaría e Intervención, con la pre- 
visión, en el artículo 99 de la Ley 7/1985, de que los méritos generales, entre los que figuran la posesión de un determinado grado personal, la valoración del trabajo desarrollado, los cursos de formación y perfeccionamiento y la antiguiedad, alcanzará el $75 \%$ de la puntuación.

\section{LA MODULACIÓN DE LOS REQUERIMIENTOS DE MÉRITO Y CAPACIDAD PARA EL ACCESO A LA FUNCIÓN DE SECRETARÍA E INTERVENCIÓN LOCAL, Y LA MODULACIÓN DEL ESQUEMA DE OBJETIVIDAD, IMPARCIALIDAD E INDEPENDENCIA EN EL EJERCICIO DE LA FUNCIÓN DE SECRETARÍA E INTERVENCIÓN LOCAL}

Sobre el esquema originario de reconocimiento y valoración de méritos generales y méritos específicos, determinantes para la resolución de los concursos de selección de funcionarios de Secretaría e Intervención locales, inciden, en el año 1993, dos textos legales, que contribuyen a alterar sensiblemente esta inicial referencia procedimental.

La Ley 10/1993, en su artículo 2, abre la vía a lo que el propio precepto califica como una vía excepcional, consistente en sustituir el sistema de concurso por el de libre designación, para los Secretarios que asuman puestos en Diputaciones Provinciales, Cabildos, Consejos Insulares, Ayuntamientos capitales de Comunidad Autónoma o de provincia y municipios de población superior a cien mil habitantes, siempre que tengan asignado nivel treinta de complemento de destino. La libre designación se introduce también, por el mismo precepto, para los Interventores que, como complemento a los requisitos antes expresados, incorporen el relativo a que el presupuesto de la Corporación local sea superior a tres mil millones de pesetas.

En ambos casos, la justificación del cambio normativo está expresado en el mismo tenor literal del artículo 2 de la Ley 10/1993: «el carácter directivo de sus funciones o la especial responsabilidad que asuman», criterio que remite a la apreciación por el Pleno de la correspondiente Corporación local, mediante acuerdo en el que quede constancia de la opción por el sistema de libre designación de Secretario o Interventor en la correlativa Relación de Puestos del Trabajo.

El mismo precepto atribuye al Pleno de la Corporación la aprobación de las bases de la convocatoria para cubrir los puestos de trabajo, con expresión de la denominación y de los requisitos para desempeñarlos. 
La inicial fijación del porcentaje del 75\% del baremo para los méritos generales, con concreción por la Corporación local del 25\% de méritos específicos a efectos de determinar la propia Corporación el perfil del puestos de trabajo, es modulada por el artículo 99.1, de la posterior Ley 22/1993, que rebaja, al 65\%, el baremo de méritos generales, cuya determinación corresponde a la Administración General del Estado, para atribuir, a la Comunidad Autónoma en la que radica la Corporación Local, el $10 \%$, con la finalidad de atender al reconocimiento de los méritos relacionados con el conocimiento de la organización y de la normativa autonómica.

La distribución de méritos generales implica, en consecuencia, el 65\% a determinar por la Administración General del Estado, y el 10\%, a determinar por la correspondiente Comunidad Autónoma, y las Corporaciones locales pueden establecer el 25\% del baremo en calidad de méritos específicos.

La incorporación de un puesto de Secretario o Interventor a la Relación de Puestos de Trabajo por las Corporaciones Locales que pueden optar por cubrir estos puestos de trabajo por el sistema de libre designación, implica el cese de los funcionarios que venían desempeñando el puesto funcionarial, estableciéndose por el artículo 99 de la Ley 10/1993, como aproximación al principio de «respeto de los derechos adquiridos, que a los funcionarios cesados se les garantizará un puesto de trabajo de subescala y categoría en la Corporación, que deberá figurar en su relación de puestos de trabajo.

El cambio operado en el electoral año de 1993 tiene su contexto en los pactos de legislatura, que tuvieron su derrotero en el Golfo de Vizcaya y en la voluntad nacionalista de desdibujar los Cuerpos Nacionales de Administración Local, y tienen cobertura complementaria en las instrumentalizadoras construcciones sintetizables en el concepto de management administrativo, orientado por providenciales gestores públicos que relativizan la «función pública» y aprecian las bondades del sustitutivo terminológico de «empleo público», con la consecuente laboralización de las situaciones jurídicas, la neutralización del principio constitucional de estructura jerárquica de la Administración Pública, y la flexibilidad de las formas de gestión, mediante la incorporación de técnicas jurídico privadas que eluden los procedimientos públicos de decisión y sus sistemas de responsabilidad en la gestión de los derechos de los ciudadanos, de los intereses públicos y de los bienes, patrimonios y recursos económicos públicos. 


\section{LA RUPTURA DEL ESQUEMA DE OBJETIVIDAD, IMPARCIALIDAD E INDEPENDENCIA EN EL EJERCICIO DE LA FUNCIÓN DE SECRETARÍA E INTERVENCIÓN LOCAL, POR LA QUIEBRA DE LA GARANTÍA DE MÉRITO Y CAPACIDAD EN EL ACCESO A LOS PUESTOS PÚBLICOS DE SECRETARIO E INTERVENTOR LOCAL}

La habilitación de la Ley 10/1993 a las Corporaciones locales para que puedan optar en los puestos más significativos por la libre designación y para que puedan configurar el $25 \%$ del baremo para acceder a los puestos de Secretario e Interventor fue objeto de recurso de inconstitucionalidad, formalizado por los Diputados del Grupo Parlamentario Popular, y objeto de la Sentencia del Tribunal Constitucional 235/2000, de 5 de octubre, de la que ha sido ponente el Magistrado Sr. Jiménez Sánchez.

Las alegaciones de inconstitucionalidad se fundan por los recurrentes en la vulneración de la reserva de ley que requiere el artículo 103.3 en la regulación de la función pública, que se considera conculcada por la discrecional intervención de las Corporaciones locales acordando, en sus Plenos Municipales, la forma de cubrir el puesto de Secretario o Interventor, pudiendo optar por la fórmula de libre designación del Secretario y del Interventor, y decidiendo sobre la configuración del $25 \%$ del baremo de méritos. También se considera conculcada la exigencia constitucional de mérito y capacidad, y de imparcialidad en el ejercicio de la función pública, requeridas por el mismo artículo 103.3.

\section{Exposición de la doctrina del Tribunal Constitucional}

La argumentación de los recurrentes para mostrar la vulneración del principio de reserva de ley por el sistema de libre designación y el diseño del $25 \%$ del baremo por acuerdo de la Corporación local, está fundada en la precisa doctrina de la jurisprudencia constitucional establecida por las Sentencia $83 / 1984$ y $99 / 1987^{3}$.

\footnotetext{
${ }^{3}$ El significado último de la reserva de ley: «es el de asegurar que la regulación de los ámbitos de libertad que corresponden a los ciudadanos depende exclusivamente de la voluntad de sus representantes, por lo que tales ámbitos han de quedar exentos de la acción del Ejecutivo y, en su consecuencia, de sus productos normativos propios, que son los reglamentos», principio que, sin embargo, «no excluye ciertamente, la posibilidad de que las Leyes contengan remisiones a normas reglamentarias, pero sí que tales remisiones hagan posible una regulación independiente a la Ley, lo que supondría una degradación de la reserva formulada por la Constitución en favor del legislador» ( FJ 4 de la STC 83/1984, de 24 de julio).
} 
En contraste con esta doctrina, el Tribunal Constitucional estima que el hecho de que la ley opere con la remisión a la potestad reglamentaria de los entes locales para la fijación de este 25 por 100, en atención, en todo caso, a la necesaria adecuación a las características del puesto de que se trate, no conculca las exigencias de la reserva de ley.

Aprecia que, así como la pormenorización de los méritos que pueden hacerse valer en el concurso como modo de provisión de los puestos de trabajo en el ámbito de la Administración del Estado, se defiere a lo dispuesto reglamentariamente ${ }^{4}$, la determinación de los méritos específicos que han de ser tomados en consideración para la provisión, mediante concurso de los puestos de trabajo reservados a funcionarios locales con habi-

La reserva de ley ofrece en el ámbito de la función pública unos rasgos peculiares: «En el primer inciso de su art. 103.3 la Constitución ha reservado a la Ley la regulación de la situación personal de los funcionarios públicos y de su relación de servicio o 'régimen estatutario', por emplear la expresión que figura en el art. 149.1.18 de la misma Norma Fundamental. Es éste, desde luego, un ámbito cuyos contornos no pueden definirse en abstracto y a priori, pero en el que ha de entenderse comprendida, en principio, la normación relativa a la adquisición y pérdida de la condición de funcionario, a las condiciones de promoción en la carrera administrativa y a las situaciones que en ésta puedan darse, a los derechos y deberes y responsabilidad de los funcionarios y a su régimen disciplinario, así como a la creación e integración, en su caso, de Cuerpos y Escalas Funcionariales y al modo de provisión de puestos de trabajo al servicio de las Administraciones Públicas, pues habiendo optado la Constitución por un régimen estatutario, con carácter general, para los servidores públicos (arts. 103.3 y 149.1.18), habrá de ser también la Ley la que determine en qué casos y con qué condiciones pueden reconocerse otras posibles vías para el acceso al servicio de la Administración Pública. Las normas que disciplinen estos ámbitos serán, en el concepto constitucional, ordenadoras del Estatuto de los funcionarios públicos, pues todas ellas interesarán directamente a las relaciones entre éstos y las Administraciones a las que sirven, configurando así el régimen jurídico en el que pueda nacer y desenvolverse la condición de funcionario y ordenando su posición propia en el seno de la Administración. Esta normación, en virtud de la reserva constitucional a la que se viene haciendo referencia, habrá de ser dispuesta por el legislador en términos tales que, de conformidad con lo antes observado, sea reconocible en la Ley misma una determinación material suficiente de los ámbitos así incluidos en el Estatuto funcionarial, descartándose, de este modo, todo apoderamiento explícito o implícito a la potestad reglamentaria para sustituir a la norma de Ley en la labor que la Constitución le encomienda. Si estos límites se respetan no podrá decirse inconstitucional la remisión legal al Reglamento, según ya se apuntó por este Tribunal en el FJ 6 de su Sentencia 57/1982» (STC 99/1987, de 11 de junio, resolutoria de la impugnación entablada contra la Ley 30/1984, de 2 de agosto, de medidas para la reforma de la función pública).

Es necesaria la intermediación, por tanto, de la ley para regular el «modo de provisión de puestos de trabajo al servicio de la Administración Pública» [STC 99/1987, FJ 3 c) y d)], sin perjuicio de la llamada al reglamento a fin de complementar o particularizar sus determinaciones [SSTC 83/1984, FJ 4, 99/1987, FJ 3 a), b) y c), y, por lo que atañe al régimen de incompatibilidades, STC 178/1989, de 2 de noviembre, FJ 7].

${ }^{4}$ Artículos. 39 a 50 del Real Decreto 364/1995, de 10 de marzo, que aprueba el Reglamento general de ingreso del personal al servicio de la Administración General del Estado y de provisión de puestos de trabajo y promoción profesional de los funcionarios civiles de la Administración General del Estado 
litación de carácter nacional, se confía a las Corporaciones Locales, permitiendo así que los méritos a valorar tengan conexión, aunque razonablemente limitada al 25 por 100 de la puntuación, con las singularidades de las Corporaciones Locales en las que se sitúan los concretos puestos de trabajo sacados a concurso.

Conforme al criterio del Tribunal Constitucional, esta opción legislativa está, sin lugar a dudas, en consonancia con el carácter de los procedimientos aquí considerados, integrados por una primera fase de selección nacional y otra subsiguiente de provisión en cada Corporación Local.

En estos términos, y con el inequívoco respaldo de la autonomía local, explicitada en los artículos 137 y 140 de la Constitución, resulta plenamente coherente, con la lógica del sistema, que el legislador haya atribuido a los entes locales interesados la fijación de un determinado porcentaje de los méritos que pueden hacerse valer en los concursos; méritos que, en todo caso, habrán de responder a las concretas características, de ahí su especificidad, del puesto de que se trate.

El Tribunal Constitucional aprecia que la especificidad, si, de un lado, hace posible el eventual control judicial, de otro, dado que tal precisión no dejaría de entrar en conflicto con el margen de libre disposición de que se ha querido investir por el legislador a los entes locales, no puede desembocar en un excesivo encorsetamiento de dicho margen mediante la fijación de grupos, tipos o categorías de méritos, que, sobre no venir exigida por la reserva de ley, reduciría injustificadamente el ámbito en el cual naturalmente pueden desplegarse las competencias de aquellos entes para especificar, en virtud de su potestad de autoorganización, las peculiaridades de los distintos puestos de trabajo.

En relación con la vulneración del principio de legalidad por el sistema de libre designación, el Tribunal Constitucional rechaza la existencia de vulneración alguna de los principios de legalidad y seguridad jurídica (arts. 1.1 y $9.3 \mathrm{CE}$ ), y aprecia que la mera previsión en norma dotada de rango de ley (y, además, básica desde la perspectiva del art. 149.1 CE), es suficiente para desvirtuar toda imputación de vulneración del primero de los citados principios.

El Tribunal Constitucional también rechaza la vulneración del principio de seguridad jurídica, que considera construido al socaire del artículo 9.3 $\mathrm{CE}$, rechazo que apoya en que «la seguridad jurídica, según constante doctrina de este Tribunal, es "suma de certeza y legalidad, jerarquía y publicidad normativa, irretroactividad de lo no favorable e interdicción de la 
arbitrariedad, sin perjuicio del valor que por sí mismo tiene aquel principio" (SSTC 27/1981, 99/1987, 227/1988 y 150/1990)» (STC 173/1996, de 31 de octubre, FJ 3).

No advierte el Tribunal Constitucional que la ordenación legal del sistema de libre designación incurra en vicio alguno contrario a las exigencias del principio de seguridad, dado que la normativa establecida, de un lado, aparece redactada con la suficiente claridad como para eliminar cualquier sombra de incertidumbre acerca de su contenido y alcance.

El Tribunal también descarta «el eventual uso torticero de la posibilidad alumbrada por la redacción que se cuestiona del art. 99.2 LBRL, o por una aplicación de ella que incurra en desviación de poder», y estima que «sobre encontrar en la jurisdicción contencioso-administrativa su cauce ordinario de control (art. 106.1 CE), no genera per se la inconstitucionalidad del precepto ante la mera eventualidad de su uso arbitrario por parte de la Administración (STC 58/1982, de 27 de julio, FJ 2)».

El alegato de vulneración de los principios constitucionales de mérito y capacidad y su incidencia en los principios de objetividad e imparcialidad en el ejercicio de la función pública, afectados por la posibilidad de libre destitución de quien ha sido designado por el sistema de libre designación con detrimento del ejercicio objetivo e imparcial, conforme al artículo 103.1 y $3 \mathrm{CE}$ de las funciones que le corresponde desarrollar (fe pública y asesoramiento legal preceptivo; control y fiscalización interna de la gestión económico-financiera y presupuestaria; contabilidad, tesorería y recaudación), es desestimada por el Tribunal Constitucional acogiendo los argumentos expresados por el Abogado del Estado, ponderado con las valoraciones sociológicas que agrega ${ }^{5}$.

El Tribunal Constitucional aprecia y estima que, sin perjuicio de reconocer que el sistema de libre designación, por su propia esencia, puede

\footnotetext{
${ }^{5}$ Conforme a la exposición del Abogado del Estado, el cese discrecional, como contrapartida a la libre designación, puede constituir «un poderoso estímulo para que el funcionario libremente designado se acomode a la directrices y criterios que profese o acepte quien tenga la facultad de usarlas». A continuación argumenta que este apreciable sacrificio de la imparcialidad funcionarial no puede desconocer que ésta no es un valor absoluto, ni siquiera allí donde, en principio, debiera venir investida de una particular protección, como es el caso del ejercicio de funciones de carácter directivo o de especial responsabilidad que constituyen, precisamente, el eslabón más alto de la organización administrativa. La argumentación concluye apreciando que el sacrificio relativo de la imparcialidad puede venir justificado en aras del aseguramiento de la «penetración administrativa de la opción política legitimada democráticamente», como trasunto de la especial relación de confianza, entre los representantes políticos democráticamente elegidos (art. 1.1 CE), y la cúspide de la organización administrativa, de corte funcionarial.
} 
matizar o debilitar la integridad de la imparcialidad a que se refiere el artículo 103.3 CE (no así, se dice, la objetividad proclamada en el art. 103.1 $\mathrm{CE}$, pues el mandato contenido en este precepto se dirige a la Administración Pública en cuanto tal, no a los funcionarios o servidores que la integran), y entiende que dicho debilitamiento ha de ser ponderado a la vista de otros elementos (vinculación, en virtud del principio democrático - arts. 1.1 y $97 \mathrm{CE}$-, del alto funcionariado local con los representantes locales democráticamente elegidos; necesidad de evitar, en expresión del defensor de la Ley recurrida, el «mandarinato», siempre pernicioso, de dicho funcionariado) cuya concurrencia, en una labor de equilibrio de los intereses en presencia, justifica plenamente, a juicio del Tribunal, la solución adoptada.

El Tribunal Constitucional constata que los principios de igualdad, mérito y capacidad, reconocidos en los artículos 23.2 y 103.3 de la Constitución, rigen, no sólo en el momento inicial del acceso a la función pública, sino también en los ulteriores de desenvolvimiento de la carrera administrativa o profesional de los funcionarios (STC 96/1997, de 19 de mayo, FJ 2), y considera que al tratarse de este segundo momento, el atinente a la provisión de puestos de trabajo, es legítima la toma en consideración, a la hora de decidir sobre aquella provisión, de otros valores o fines constitucionalmente lícitos. En este sentido constata el Tribunal que así se ha dicho, con relación a los principios de protección de la familia (art. 39.1 CE) y de eficacia de la Administración (art. 103.1 CE), a propósito del llamado turno de consorte en los concursos de traslado de los funcionarios (SSTC 192/1991, de 14 de octubre, FJ 4, 200/1991, de 28 de octubre, FFJJ 3 y 4, con cita, en ambos casos, del ATC 1325/1988, de 19 de diciembre), o, a fin de hacer efectivo el principio de autonomía de los entes territoriales, como modulación del derecho de igualdad, en los casos de movilidad interadministrativa, ex art. 17 de la Ley 30/1984 (STC 156/1998, de 13 de julio, FFJJ 3 y 4 ).

Para el Tribunal Constitucional tanto el concurso como la libre designación, aunque esta última venga establecida, ex artículo 99.2 de la Ley Básica de Régimen Local, con carácter excepcional, excepcionalidad que justifica con los razonamientos que preceden acerca de los principios de mérito y capacidad, son sistemas o modos de provisión de puestos de trabajo entre quienes ya ostentan la condición de funcionarios con habilitación de carácter nacional.

La finalidad a que ambos sirven, conforme al criterio del Tribunal Constitucional, es la misma: la atribución, de acuerdo con la lógica de cada procedimiento, de determinados puestos de trabajo a aquellos fun- 
cionarios en quienes concurran, desde la óptica de los principios de mérito y capacidad, la cualificación e idoneidad precisas para el mejor y más correcto desempeño de las funciones que corresponden a cada puesto.

Para el Tribunal Constitucional el dato de que la adjudicación sea, en el caso del concurso, la consecuencia de la baremación, más o menos automática, de los méritos aportados, según lo dispuesto en la oportuna convocatoria, en tanto que en el sistema de libre designación se produzca como resultado de la apreciación (dotada, como es obvio, de una evidente connotación de discrecionalidad o, si se prefiere, de un cierto margen de libertad) que el órgano decisor se haya forjado a la vista del historial profesional de los candidatos o aspirantes, es indiferente desde la perspectiva del genérico estatuto funcionarial de la persona que finalmente resulte adjudicataria del puesto en cuestión.

El Tribunal aprecia que no nos hallamos aquí en presencia de nombramientos para cargos políticos, caracterizados por la libérrima decisión de quien sea competente para efectuar el nombramiento; ni ante la designación de personal eventual, cualificado, según el artículo 20.2, párrafo segundo, de la Ley 30/1984, por la «confianza o asesoramiento especial» de las funciones que pueden encomendársele. La confianza que, en este sentido, puede predicarse de la libre designación, en cuanto modo de provisión entre funcionarios de puestos de trabajo, es la que se deriva de la aptitud profesional del candidato, puesta de manifiesto en los méritos esgrimidos, esto es, en su historial funcionarial.

El Tribunal considera que la libre designación como forma de provisión de un puesto de trabajo alude a un régimen jurídico que, presenta singularidades en la forma de nombrar a un funcionario para el puesto concreto, y también las ofrece en relación con la forma en que dicho funcionario puede ser cesado. Constata que la imparcialidad en el ejercicio de la función pública, en las relaciones con los administrados, está garantizada por una serie de cautelas legales, entre las que ocupa un lugar destacado la obligación de abstención y la posibilidad de recusación de los funcionarios cuando concurren determinadas circunstancias previstas legalmente que pueden poner en peligro objetivo la rectitud de su actuación (arts. 28 y 29 de la Ley 30/1992), y que lo que está en cuestión es la vertiente interna de la imparcialidad, es decir, si la facultad de que el Presidente de la Corporación cese discrecionalmente en su puesto de trabajo al funcionario nombrado para él a través del sistema de libre designación coloca a dicho funcionario en una posición de debilidad tal que pueda comprometer la imparcialidad en el ejercicio de sus funciones. 
El Tribunal Constitucional estima que el libre cese que acompaña a la libre designación no es incompatible en abstracto con el ejercicio imparcial de las funciones públicas. La Ley impugnada configura el sistema con ciertas garantías suplementarias en atención a la importancia de las funciones atribuidas a estos funcionarios. Su nombramiento es decidido por el Presidente de la Corporación de entre quienes ya cuentan con habilitación nacional y cumplen los requisitos de la convocatoria; ha de haberse modificado previamente la correspondiente relación de puestos de trabajo para fijar el sistema de libre designación como forma de provisión del puesto de trabajo (art. 99.2 párrafo 1 de la norma impugnada), lo cual corresponde al Pleno de la Corporación por aplicación de los artículos 22.2 i) y 33.2 f) de la Ley 7/1985, de 2 de abril, reguladora de las Bases del Régimen Local; es el Pleno de la Corporación el que aprueba las bases de la convocatoria.

Para el Tribunal, la intermediación del Pleno corporativo significa, en suma, una autorización al Presidente por parte del órgano supremo de la Corporación, sin la cual el sistema de libre designación no puede ser aplicado.

En contraste con la intermediación del Pleno en el nombramiento, el cese puede ser acordado por el Presidente de la Corporación y, el Tribunal Constitucional, aprecia que, si bien el artículo 99.2 párrafo 2 impugnado no dice expresamente que tenga carácter discrecional, parece presuponerlo, como lo confirma el desarrollo reglamentario (art. 29 del Real Decreto 1732/1994, de 29 de julio, sobre provisión de puestos de trabajo reservados a funcionarios de Administración local con habilitación de carácter nacional).

No obstante, el Tribunal aprecia que, también en este aspecto, la regulación legal cuya constitucionalidad se cuestiona otorga alguna garantía suplementaria al funcionario cesado libremente, y cita el artículo 20.1 e) de la Ley 30/1984, de 2 de agosto, de medidas para la reforma de la función pública, que nada prevé en cuanto al destino del funcionario cesado, si bien el artículo 58 del Real Decreto 364/1995, de 10 de marzo, por el que se aprueba el Reglamento general de ingreso del personal al servicio de la Administración General del Estado y de provisión de puestos de trabajo y promoción profesional de los funcionarios civiles de la Administración General del Estado, garantiza al funcionario cesado la adscripción provisional a un puesto de trabajo correspondiente a su cuerpo o escala, no inferior en más de dos niveles al de su grado personal en el mismo municipio, en tanto no obtenga otro con carácter definitivo. 
En contraste con los funcionarios civiles de la Administración General del Estado, aprecia el Tribunal que los preceptos impugnados, de rango legal, garantizan al funcionario cesado un puesto de trabajo de su subescala y categoría en la Corporación que tendrá asignadas funciones de «colaboración, apoyo y asistencia jurídica o económica», y que deberá figurar en la correspondiente relación de puestos de trabajo, lo que constituye una garantía suplementaria para el funcionario que mitiga razonablemente las consecuencias que la pérdida de confianza inherente al cese le pudieran acarrear, y por ende le colocan en una mejor posición para ejercer sus funciones con la imparcialidad requerida.

El Tribunal Constitucional concluye afirmando que el sistema de libre designación para puestos de indudable relevancia por su carácter directivo y especial responsabilidad no es en abstracto contrario al artículo 103.3 $\mathrm{CE}$, ni tampoco en el presente supuesto, aun partiendo de la importancia de las funciones de asesoramiento legal y económico, o de control financiero y presupuestario encomendadas a los funcionarios con habilitación nacional, no queda comprometida la imparcialidad que la ley debe preservar para el ejercicio de las funciones públicas según el citado artículo, y tampoco hay vulneración del principio de objetividad (art. 103.1 CE), que, aplicable a todas las Administraciones Públicas (STC 85/1983), tiene por destinatarias a éstas, justamente, en cuanto sujetos de Derecho.

\section{Valoración de la doctrina del Tribunal Constitucional}

A los Diputados demandantes y al Tribunal Constitucional les ha pasado desapercibido un dato: el carácter básico para el régimen jurídico de las Administraciones locales de los Cuerpos de Habilitación Nacional.

El carácter básico de los Cuerpos de Habilitación Nacional obliga a operar con un sistema homogéneo de designación de sus miembros: Secretarios e Interventores, cuya regulación corresponde solo a la Ley y que, por ello, debe estar sustraído a las posibles ocurrencias del ejecutivo.

El carácter básico de los Cuerpos de Habilitación Nacional requiere justificar el cambio en las Bases y adecuar el posible cambio al doble vínculo que define la posición jurídica de los Cuerpos de Habilitación Nacional, disociación expresada con fortuna en el artículo 92.2 de la Ley Básica de Régimen Local de 1985, entre el Estado y la Corporación local, a efectos de vertebrar el Estado desde las Corporaciones locales que en sí mismas son también Estado, conforme a la ejemplar descripción del Estado del artículo 137 de la Constitución. 
El Tribunal Constitucional, aunque opera con el argumento de los logros conseguidos por la Sentencia, que enjuició la Ley de 1985, y que evitó la regionalización de los concursos de Secretarios e Interventores, no repara en que el efecto del artículo 2 de la Ley 10/1993, al dar nueva redacción al artículo 99 de la Ley 7/1985, provoca la fragmentación no en diecisiete referencia autonómicas sino en el centenar largo de Corporaciones locales afectadas por la posibilidad de configurar baremos personalizados para los secretarios e interventores de la mayoría política que decide utilizar el sistema de libre designación de Secretarios e Interventores.

El Tribunal Constitucional incurre en el grave error de identificar los Cuerpos de Habilitación Nacional con el resto de los cuerpos de la función pública, sin reparar en las peculiaridades institucionales que definen las singulares funciones y responsabilidades públicas de Secretarios e Interventores de la Administración Local, que contribuyen con la prestación de sus funciones públicas a vertebrar el conjunto de entes que forman la Administración Local del Estado descentralizado, con el trascendente objetivo institucional de garantizar la igualdad de derechos de los vecinos de los distintos municipios que son ciudadanos de un mismo Estado.

En contraste con los distintos cuerpos de funcionarios civiles de la Administración General del Estado y de las Comunidades Autónomas, e incluso de los restantes funcionarios de la Administración local, los Secretarios e Interventores son responsables de los correlativos procedimientos administrativos de la correspondiente Corporación, perspectiva que pasa desapercibida a los recurrentes y al Tribunal Constitucional y que incide en el carácter básico de su función en correlación con las cualificadas aportaciones de la Ley 30/1992 como Ley básica del régimen jurídico de las Administraciones Públicas y, al tiempo, del procedimiento administrativo común.

En contraste con la banalización de que es objeto por el Tribunal Constitucional la profesionalidad de la función pública y la neutralidad política, garantizada por la objetividad de los concurso articulados por los principios de mérito y capacidad, los Cuerpos de Habilitación Nacional, y las específicas funciones públicas de Secretarías e Intervenciones de Administración Local, debieran haber sido consideradas como un imprescindible y autorizado precedente para la recuperación de las correctas prácticas administrativas procedimentales que requiere la aplicación de la Ley 30/1992-4/1999, para materializar las bases del régimen jurídico de las Administraciones públicas y el procedimiento administrativo común y hacer efectivos los derechos ciudadanos que enuncia requiere recuperar la función pública de Secretaría e Intervención. 
El Tribunal Constitucional, al ignorar el carácter básico de la configuración de los Cuerpos de Habilitación Nacional, en menoscabo de la garantía ciudadana e institucional de que las cerca de las nueve mil Entidades locales, entre Corporaciones locales y entidades asociativas en las que se integran, confluyan, de modo armónico, en el sistema jurídico y económico que define el Ordenamiento Jurídico del Estado, unido a la desafortunada identificación que el Tribunal Constitucional realiza de Secretarios e Interventores de la Administración Local con los Cuerpos de Funcionarios Civiles del Estado, introduce en los Cuerpos de Habilitación Nacional las prácticas políticas que han transformado la función pública en empleo público y que bloquea en las sucesivas legislaturas la elaboración del Estatuto de la Función Pública, en detrimento del reto de una Administración pública racionalizada, que marcó la irreductible línea de reflexión institucional que rigió la vida y la obra del Profesor Sebastián MARTín-RetortiLlo. 